\title{
MOTIVASI PELANGGAN RESTORAN DI BANDUNG KETIKA MAKAN DI LUAR RUMAH
}

\author{
Taufik Abdullah \\ Manajemen Pemasaran Pariwisata, Universitas Pendidikan Indonesia \\ taufikabdullah@upi.edu
}

\begin{abstract}
ABSTRAK
Bandung adalah kota yang terkenal dengan wisata belanja dan wisata kulinernya. Pertumbuhan industri jasa penyediaan makanan dan minuman berkembang pesat di Bandung. Hal ini turut memperkuat Bandung sebagai destinasi wisata kuliner dan menarik wisatawan dan masyarakat lokal untuk menikmati makan di berbagai bisnis kuliner tersebut khususnya saat liburan akhir pekan. Penelitian ini dilakukan untuk mengetahui motivasi pelanggan membeli makanan dan minuman di luar rumah, sehingga para pengusaha dapat menerapkan strategi yang tepat jika mengetahui alasan pelanggan menikmati makanan dan minuman di luar rumah. Jenis penelitian ini adalah penelitian deskriptif kualitatif. Teknik pengumpulan data yang digunakan adalah kuesioner yang disebarkan kepada sampel sebanyak 100 responden. Populasi dalam penelitian ini adalah pelanggan industri jasa penyediaan makanan dan minuman khususnya restoran di kota Bandung. Dari hasil penelitian diketahui bahwa motivasi tertinggi pelanggan dalam membeli makanan dan minuman di luar rumah adalah untuk mendapatkan variasi makanan dan minuman.
\end{abstract}

Kata Kunci: Motivasi Pelanggan, Makan di Luar Rumah

\section{RESTAURANT CUSTOMER MOTIVATION WHEN EATING OUTSIDE IN BANDUNG}

\begin{abstract}
Bandung is a city known as a shopping and culinary destination. Food and Beverage industry develop significant followed by the increasing number of tourists and also many local communities enjoy dining out in many food and beverage establishment especially on the weekend. This study was conducted to gather the information about the reason or motivation of the customer eating outside their home, so the businessman in Food and Beverage industry could apply more suitable strategy after they know those motives. This is a descriptive and qualitative study. Data were collected by questionnaires, from 100 samples. The population of the studies is Food and Beverage Industry's customer who eat
\end{abstract}


outside their home. This study shows that the highest motivation for eating outside home is because the the food variety offered by the industries.

\section{Keywords: Customer Motivation, Dining Out}

\section{PENDAHULUAN}

Perkembangan hidup manusia di muka Bumi sangat cepat berubah. Kemajuan di bidang teknologi, informasi dan komunikasi mengarahkan gaya hidup manusia menjadi lebih mobile dan global. Informasi menjadi sangat cepat tersampaikan, komunikasi dapat dilakukan dengan mudah serta akses menuju suatu tempat menjadi lebih terbuka sehingga batasan akan ruang dan waktu semakin lama semakin tidak terlalu terasa. Perkembangan tersebut menyebabkan munculnya berbagai gaya hidup bagi masyarakat modern.

Salah satu gaya hidup yang pertumbuhannya sangat pesat dari masa ke masa adalah gaya hidup menikmati makan dan minum di luar rumah. Berdasarkan data dari Tribunnews.com. Sepanjang tahun 2013, tercatat kunjungan orang Indonesia ke restoran mencapai 380 juta kali dan menghabiskan total USD 1,5 miliar, serta pencarian restoran secara online sepanjang 2013 mencapai 40 juta kali. Peningkatan tersebut diikuti dengan pertumbuhan restoran kelas menengah dan atas hingga 250 persen dalam lima tahun terakhir (Data diunggah tahun 2014). Data tersebut merupakan data nasional, walaupun data per provinsi ataupun kota dan kabupaten tidak tersedia, namun fenomena yang terjadi pada gaya hidup makan di luar rumah ini sangat luar biasa. Bagi para pengusaha jasa penyediaan makanan dan minuman tentu ini adalah potensi pasar yang perlu diraih. Mereka perlu menyediakan makanan dan minuman yang sesuai dengan apa yang dibutuhkan dan diinginkan pasar. Kebutuhan dan keinginan dari konsumen ini merupakan pembentuk motivasi ataupun alasan mengapa konsumen mengkonsumsi makanan di luar rumahnya.

Studi ini berada dalam ranah perilaku konsumen sebagai bagian dari pemasaran. Menurut Hoyer, et. al. (2013, hlm. 14), penelitian mengenai perilaku konsumen memberikan informasi yang penting bagi manajer pemasaran untuk mengembangkan strategi dan taktik marketing. Sehingga dengan kegiatan marketing, para marketing manajer dapat mengetahui nilai-nilai apa yang dimiliki konsumen sehingga dapat menciptakan dan menyampaikan barang ataupun jasa sesuai nilai yang diinginkan atau dibutuhkan konsumen. Davis, et. al. (2008:28) juga menyebutkan bahwa pemahaman akan faktor-faktor yang mempengaruhi keputusan pembelian pelanggan dan menganalisis siapa yang makan di luar serta frekuensi mereka melakukannya adalah data yang sangat berharga bagi Food and Beverage Manager.

Bandung merupakan suatu destinasi wisata yang terkenal dengan wisata belanja dan wisata kulinernya. Adanya citra yang terbentuk pada Kota Bandung tentu dikarenakan produk makanan dan minuman yang bervariasi dan kualitas yang diberikannya. Pada saat akhir minggu Bandung selalu padat dengan banyaknya wisatawan yang datang, baik itu wisatawan yang memang bertujuan utama untuk menikmati makanan dan minuman di Bandung, ataupun produk 
makanan dan minuman sebagai daya tarik kedua, serta wisatawan yang menikmati makanan dan minuman hanya untuk memenuhi kebutuhan dasar. Seluruh wisatawan tersebut tetap saja akan makan dan minum di Bandung. Apabila alasan ataupun motivasinya diketahui, maka pihak pengelola dapat menerapkan strategi pemasaran yang lebih tepat agar kepuasan pelanggan lebih maksimal. Atas dasar latar belakang tersebut maka tujuan dari penelitian ini adalah untuk mengetahui motivasi pelanggan di Bandung dalam membeli makanan dan minuman di luar rumah.

\section{KAJIAN PUSTAKA}

Manusia selalu berusaha memenuhi kebutuhan yang salah satunya adalah kebutuhan akan makanan dan minuman. Dalam kegiatan pariwisata, kebutuhan ini juga tidak terlepaskan. Wisatawan masih memerlukan asupan makanan dan minuman selama melaksanakan kegiatan wisata, bahkan dengan perkembangan gaya hidup masyarakat, teknologi dan informasi, transportasi serta inovasi yang dilakukan para pengusaha jasa penyediaan makanan dan minuman, maka muncul kegiatan pariwisata yang disebut dengan food tourism. Menurut World Food Travel Association (WFTA) dalam Stanley dan Stanley (2015:3) Food tourism adalah suatu pencarian dan menikmati pengalaman makan dan minum yang unik dan terkenang, baik jarak jauh maupun jarak dekat.

Dari sisi perspektif konsumen, Stanley dan Stanley (2015:5-7) menyebutkan bahwa terdapat beberapa kunci penggerak kegiatan wisata kuliner

1. Tingginya perhatian akan peningkatan nutrisi

2. Meningkatnya urbanisasi dalam masyarakat

3. Adanya populasi yang menua

4. Popularitas makan di luar rumah telah meningkat

5. Pertanian sebagai destinasi wisata keluarga yang menyenangkan

6. Internet

Kegiatan wisata kuliner tidak lepas dengan sejarah manusia makan di luar rumah. Dalam bukunya Walker (2014:5-6) menjelaskan bahwa sejarah makan di luar rumah sangat panjang. Taverns mulai ada pada 1700 SM. Tempat makan publik yang terekam pada Mesir kuno berasal dari sekitar 512 SM dengan menu yang terbatas. Masyarakat di jaman Roma kuno juga merupakan masyarakat yang memiliki budaya makan di luar. Bukti ini dapat terlihat di Herculaneum, sebuah kota Roma dekat Naples, bahwa pada tahun 70 setelah masehi terkubur di bawah 65 kaki lumpur dan lava hasil dari erupsi Gunung Vesuvius, Di sepanjang jalan terdapat counter snack bars, vending bread, cheese, wine, dan sebagainya. Sejumlah snack bars ini identik atau mendekati sehingga menciptakan impresi bahwa mereka bagian dari suatu kelompok dengan kepemilikan yang sama.

Setelah keruntuhan Roma, makan di luar biasanya dilakukan di penginapan atau tavern, namun pada tahun 1200 terdapat cooking houses di London, Paris dan tempat lainnya di Eropa, dimana makanan yang telah dimasak dapat dibeli namun tidak terdapat tempat duduk untuk makan di tempat tersebut. Para pelaku perjalanan di abad pertengahan makan di penginapan, taverns, hostel dan monasteries. 
Café pertama berdiri di Konstantinopel pada tahun 1550 dengan bentuk coffeehouse, asal kata café sendiri berasal dari kata Perancis yang berarti coffee. Coffeehouse yang muncul di Oxford pada tahun 1650 dan tujuh tahun kemudian di London, adalah awal mula restoran saat ini. Pada saat itu kopi dianggap sebagai penyembuh berbagai penyakit. Pada abad ke 18 sudah terdapat 3000 coffeehouses di London. Coffeehouses juga popular di daerah colonial Amerika. Di Boston banyak terdapat coffeehouses begitu juga di Virginia dan New York.

Pada abad ke 18, dengan pengecualian bagi penginapan yang utamanya bagi pelaku perjalanan, makanan luar rumah dapat dibeli di tempat-tempat dimana minuman alkohol dijual. Tempat tersebut dibuat dengan konsep penyajian yang sederhana, makanan yang tidak mahal baik yang dimasak di sana ataupun yang dibeli di penginapan ataupun toko makanan. Tavern restaurants banyak ditemukan di Eropa, termasuk Perancis dan Jerman.

Stanley dan Stanley $(2015: 26)$ menjelaskan bahwa trend dari konsumen yang membeli makanan dan minuman sesuai dengan trend report 2014 adalah sebagai berikut.

1. Status seekers, trend ini menunjukkan bahwa pencari status terefleksi pada kesiapan konsumen dalam membayar makanan yang premium.

2. It is all about you, hasil dari wawancara yang dilakukan trend report, $47 \%$ menyatakan bahwa konsumen mau berbagi lokasinya via mobile device dan menerima informasi melalui alat tersebut. Hal ini mengindikasikan destinasi wisata kuliner dapat mengundang keikutsertaan konsumen menggunakan mobile device.

3. Local love, bisnis yang mengutamakan isu-isu hal yang bersifat lokal akan menjadi penilaian penting bagi konsumen.

4. Guilt-free consumption, konsumen khususnya wisatawan kuliner mengharapkan pebisnis lebih mengutamakan etika dan mengarah pada konsumsi yang bersifat berkelanjutan.

Trend akan bagaimana manusia menikmati makanan dan minuman sangat berkaitan dengan konsep perilaku konsumen. Hoyer, et. al. (2013, hlm. 3) menyampaikan bahwa perilaku konsumen adalah total keputusan konsumen dalam mengakuisisi, konsumsi, dan disposisi dari barang, jasa, aktivitas, pengalaman, orang dan ide melalui pengambilan keputusan. Solomon (2013, hlm. 7) menjelaskan bahwa perilaku konsumen adalah studi mengenai proses yang terlibat ketika individu atau kelompok memilih, membeli, menggunakan, atau membuang suatu produk, jasa, ide atau pengalaman untuk memuaskan kebutuhan dan hasrat. Kedua definisi tersebut memiliki kesamaan yang mana perilaku konsumen ini merupakan urutan kegiatan mulai dari memilih hingga selesai mengonsumsi suatu produk ataupun jasa.

Hoyer, et. al. (2013, hlm. 10) menyatakan bahwa faktor yang mempengaruhi perilaku konsumen adalah; 1) the psychological core, 2) the process of making decisions, 3) the consumer's culture, dan 4) consumer behavior outcomes. Diantara seluruh faktor tersebut, terdapat faktor yang berasal dari dalam diri konsumen yaitu psychological core. The Psychological Core merupakan proses yang terjadi dalam diri konsumen sebelum konsumen membuat keputusan, tentunya konsumen harus memiliki informasi ataupun pengetahuan 
yang menjadi dasar dalam pembuatan keputusan, berbagai sumber tersebut adalah motivasi, kemampuan, peluang; keterbukaan, perhatian, persepsi dan komprehensi; ingatan dan pengetahuan; dan sikap terhadap suatu penawaran (Hoyer, et. al., 2013, hlm. 11).

Peran motivasi menjadi sangat penting dalam psychological core karena dari artinya saja motivasi adalah suatu penggerak yang diciptakan oleh ketertarikan dan kebutuhan konsumen (Hawkins dan Mothersbaugh, 2010, hlm. 290). Sedikit berbeda menurut Hoyer, et. al. (2013, hlm. 45), motivasi adalah keadaan gairah di dalam diri yang menyediakan energi yang dibutuhkan untuk mencapai suatu tujuan. Sedangkan Solomon (2013, hlm. 118) menyampaikan bahwa motivasi mengacu pada suatu proses yang mengarahkan orang berperilaku seperti yang mereka lakukan. Motivasi ini bisa berasal dari internal maupun eksternal, namun Hoyer, et. al. (2013, hlm. 48) menjelaskan bahwa sesuatu hal dapat berpengaruh bagi motivasi apabila; 1) Secara personal relevan, 2) Konsisten dengan nilai, kebutuhan, tujuan, emosi dan proses pengendalian diri, 3) Resiko, dan 4) Cukup konsisten dengan sikap mereka sebelumnya.

Solomon (2013, hlm. 16) menyatakan: "people often buy products not for what they do but for what they mean", yang berarti orang sering membeli produk bukan karena apa yang bisa dilakukan produk tersebut, tapi karena berartinya produk bagi orang tersebut. Prinsip ini bukan berarti fungsi utama dari produk tidak penting, namun lebih kepada peran produk tersebut jauh lebih baik melebihi tugas utamanya, Semakin dalam makna suatu produk dapat membantunya bersaing dari para pesaing yang menyediakan barang dan jasa serupa.

ICTA dan ICTD 'State of the Culinary Tourism Industry Report' dalam Stanley dan Stanley (2015:27) menyebutkan beberapa jenis wisatawan kuliner sebagai berikut.

1. Adventure travellers; merupakan pelaku perjalanan yang melakukan perjalanan jauh untuk mendapatkan petualangan dalam mencari makanan.

2. Ambiance travellers; merupakan orang yang lebih mencari pengalaman daripada mencari jenis makanan tertentu.

3. Authentic travellers; mereka cenderung ingin menikmati makanan yang otentik.

4. Budget; uang merupakan pertimbangan utama.

5. Eclectic; orang yang mencari dan mencoba berbagai macam makanan seluasluasnya

6. Gourmet foodies; Penikmat makanan yang termahal dan terbaik.

7. Innovative travellers; para pencari makanan yang inovatif dengan ide terbaru.

8. Localists; mereka menginginkan makanan yang diproduksi secara lokal.

9. Novices; mereka yang masih baru dalam melakukan petualangan kuliner.

10. Organic food consumers; mengutamakan makanan yang organik.

11. Social food travellers; ketika menikmati makanan lebih mengutamakan interaksi sosial.

12. Trendy foodies; para pencari makanan yang sedang trend di masyarakat.

13. Vegetarians.

Diantara jenis-jenis wisatawan tersebut, lima jenis wisata yang memiliki ranking tertinggi adalah localists, novices, eclectic, organic dan authentic. 
Barrows, Powers dan Reynolds (2012:73) secara jelas mengungkapkan bahwa orang makan di luar dengan berbagai alasan, termasuk di dalamnya melepaskan diri dari rasa bosan, untuk bersosialisasi, untuk menghindari pekerjaan yang menjenuhkan, untuk dilayani, untuk mendapatkan makanan yang berbeda dari di rumah dan untuk kemudahan atau kenyamanan. Berdasarkan penjelasan sebelumnya, dimensi yang diambil dalam penelitian ini untuk mengetahui motivasi dalam menyantap makanan di luar rumah diambil dari Gillespie dan Cousins (2011: 25) yang menjelaskan bahwa alasan orang makan di luar rumah dibagi menjadi tujuh yaitu:

1. Convenience, sebagai contoh tidak dapat pulang ke rumah karena sedang berbelanja, kerja atau berwisata

2. Variety, sebagai contoh mencoba pengalaman baru atau istirahat sejenak dari memasak di rumah

3. Labour, sebagai contoh agar ada orang lain yang menyiapkan, menyajikan dan mencuci atau sederhananya secara fisik tidak memungkinkan mengadakan event di rumah

4. Status, sebagai contoh makan siang dengan tujuan bisnis atau makan di luar karena komunitas sosialnya melakukan hal yang sama

5. Culture/tradition, contohnya apabila ada event yang spesial atau bahkan lebih simpel ini adalah media untuk mengenal orang lain

6. Impulse, contohnya adalah karena adanya kebutuhan akan makanan yang harus segera dipenuhi karena rasa lapar

7. No choice, tidak ada pilihan di sini berati karena tidak dapat memilih untuk makan di rumah disebabkan karena perang, berada di rumah sakit dan sebagainya.

Motivasi ataupun alasan orang berbuat sesuatu biasanya digerakkan oleh berbagai kebutuhan atau keinginan. Lillicrap dan Cousins (2010:10) menyampaikan bahwa beberapa kebutuhan yang pelanggan mungkin berusaha penuhi demi mencapai kepuasan adalah:

1. Physiological: sebagai contoh kebutuhan untuk memuaskan rasa lapar atau haus dahaga, atau kebutuhan asupan makanan tertentu bagi penderita diabetes.

2. Economic: contohnya kebutuhan akan nilai yang baik, pelayanan yang cepat dan lokasi yang sesuai

3. Social: contohnya pergi bersama teman atau kolega bisnis, menghadiri acaraacara untuk bertemu orang lain

4. Psychological: sebagai contoh: kebutuhan untuk meningkatkan penghargaan diri, memenuhi kebutuhan gaya hidup, kebutuhan akan variasi dari hasi iklan dan promosi.

5. Convenience: contohnya pencarian kebutuhan akan asupan makanan dan minuman karena tidak dapat pulang ke rumah (Berbelanja atau kerja), mengunjungi event, hasrat agar orang lain yang mengerjakan pekerjaan, tidak mampu secara fisik menyediakan acara seperti pernikahan di rumah. 


\section{METODOLOGI PENELITIAN}

Penelitian ini dilakukan untuk mengetahui gambaran fenomena gaya hidup makan di luar rumah yang semakin hari semakin meningkat. Responden pada penelitian ini adalah pelanggan usaha jasa penyediaan makanan dan minuman di Bandung. Penelitian ini adalah penelitian deskriptif kualitatif karena hasil analisisnya adalah menggambarkan motivasi pelanggan restoran sehingga makan di luar rumah. Teknik pengumpulan data yang digunakan dalam penelitian ini adalah kuesioner. Kuesioner dibuat berdasarkan operasionalisasi variabel dimana tabelnya dapat terlihat sebagai berikut.

Tabel 1

Operasionalisasi Variabel

\begin{tabular}{|c|c|c|c|c|}
\hline Variabel & Dimensi & Indikator & Skala & No. Item \\
\hline \multirow{7}{*}{$\begin{array}{l}\text { Motivasi } \\
\text { Eating } \\
\text { Out } \\
\text { (Gillespie } \\
\text { dan } \\
\text { Cousins, } \\
2011, \\
\text { hlm. 25) }\end{array}$} & Convenience & $\begin{array}{l}\text { Kenyamanan ketika menikmati } \\
\text { makanan dan minuman }\end{array}$ & Ordinal & 1 \\
\hline & Variety & Variasi makanan dan minuman & Ordinal & 2 \\
\hline & Labour & $\begin{array}{l}\text { Kemudahan karena orang lain yang } \\
\text { menyiapkan }\end{array}$ & Ordinal & 3 \\
\hline & Status & Mengejar status & Ordinal & 4 \\
\hline & Culture/Tradition & Menghadiri suatu event & Ordinal & 5 \\
\hline & Impulse & $\begin{array}{l}\text { Dorongan kebutuhan akan makanan } \\
\text { dan minuman yang mendadak harus } \\
\text { segera dipenuhi }\end{array}$ & Ordinal & 6 \\
\hline & No Choice & Tidak ada pilihan lain & Ordinal & 7 \\
\hline
\end{tabular}

Populasi dalam penelitian ini adalah pelanggan usaha jasa penyediaan makanan dan minuman di Kota Bandung. Populasi ini dipilih karena para pelanggan tersebut adalah merupakan wisatawan ataupun masyarakat lokal yang menyantap makanan di luar rumah namun membeli makanannya di usaha jasa penyediaan makanan dan minuman di Kota Bandung. Jumlah populasi ini sangat banyak dan sulit untuk diukur. Maka dari itu teknik sampling yang digunakan adalah non probability sampling, yang secara lebih sepesifik yaitu sampling kuota. Menurut Utama dan Mahadewi (2012, hlm. 74) sampling kuota ini adalah peneliti menentukan sejumlah sampel yang memiliki ciri-ciri tertentu dan jumlah tersebut dijadikan target atau kuota yang akan berusaha dipenuhi. Ciri-ciri yang diterapkan dalam penelitian ini adalah pelanggan yang membeli makanan di luar rumah atau di restoran yang terletak di Kota Bandung. Sampel yang diteliti berjumlah 100 responden.

Analisis data yang digunakan adalah analisis deskriptif. Analisis data deskriptif yang digunakan dalam penelitian ini adalah untuk mendeskripsikan variabel yang diteliti, yaitu motivasi pelanggan dalam membeli dan menikmati makanan dan minuman di luar rumah. Dalam analisis data deskriptif, setelah tabulasi data selesai dilakukan, maka dihitung skor dari jawaban responden, termasuk rata-rata jawaban responden yang kemudian dianalisis secara deskriptif. 


\section{HASIL DAN PEMBAHASAN}

Pengukuran motivasi pelanggan dalam melakukan pembelian makanan dan minuman di luar rumah menggunakan dimensi dari Gillespie dan Cousins, 2011, hlm. 25), yaitu convenience, variety, labour, status, culture/tradition, impulse, dan no choice. Berdasarkan hasil survey yang telah dilakukan maka dapat terlihat pada tabel berikut ini.

\section{Tabel 2}

Tanggapan Responden Mengenai Motivasi Membeli Makanan dan Minuman di Luar Rumah

\begin{tabular}{|c|c|c|c|c|}
\hline No & Dimensi & Indikator & $\begin{array}{c}\text { Rata-Rata } \\
\text { Jawaban }\end{array}$ & Kategori \\
\hline 1 & Convenience & $\begin{array}{l}\text { Kenyamanan ketika menikmati } \\
\text { makanan dan minuman }\end{array}$ & 2,94 & $\begin{array}{l}\text { Ragu- } \\
\text { Ragu }\end{array}$ \\
\hline 2 & Variety & Variasi makanan dan minuman & 3,99 & Setuju \\
\hline 3 & Labour & $\begin{array}{l}\text { Kemudahan karena orang lain yang } \\
\text { menyiapkan }\end{array}$ & 3,75 & Setuju \\
\hline 4 & Status & Mengejar status & 2,46 & $\begin{array}{l}\text { Kurang } \\
\text { Setuju }\end{array}$ \\
\hline 5 & Culture/Tradition & Menghadiri suatu event & 3,57 & Setuju \\
\hline 6 & Impulse & $\begin{array}{l}\text { Dorongan kebutuhan akan makanan } \\
\text { dan minuman yang mendadak harus } \\
\text { segera dipenuhi }\end{array}$ & 3,46 & Setuju \\
\hline 7 & No Choice & Tidak ada pilihan lain & 3 & $\begin{array}{l}\text { Ragu- } \\
\text { Ragu }\end{array}$ \\
\hline
\end{tabular}

Dari hasil survey yang dapat terlihat di tabel 2, Nilai rata-rata tertinggi adalah dimensi variasi. Sehingga motivasi terkuat dari pelanggan ketika makan dan minum di luar rumah adalah karena mencari makanan dan minuman yang lebih bervariasi, atau dengan kata lain di luar kebiasaan juga bisa diartikan mencari makanan dan minuman yang baru. Pelanggan menjawab bahwa mereka kurang setuju apabila motivasi membeli makanan dan minuman di luar rumah karena mengejar status. Walaupun banyak masyarakat yang terbawa trend memfoto makanan dan minuman serta "check in" ketika berada di suatu restoran besar, yang mana hal ini identik dengan aktivitas untuk meningkatkan status, namun kenyataannya responden menjawab bahwa mereka kurang setuju bahwa kegiatan makan di luar rumah karena mengejar status. 
Menyantap makanan dan minuman di luar rumah karena merasa lebih nyaman

(100 responses)

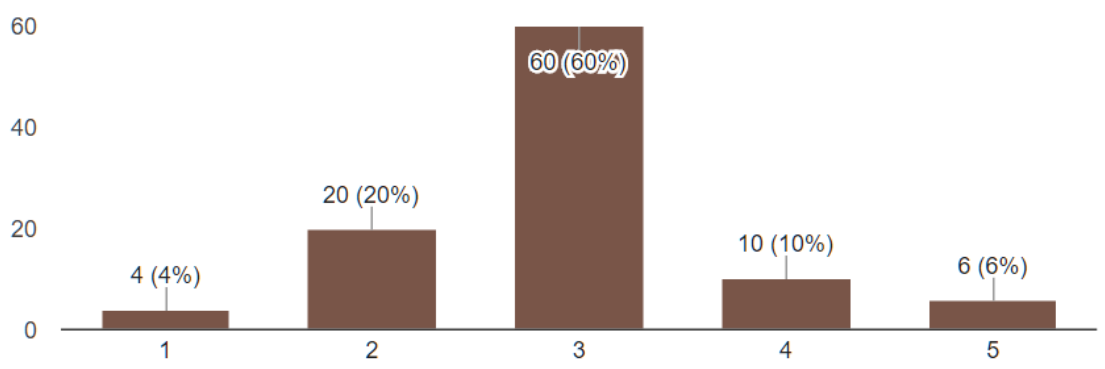

Gambar 1

Sebaran Data Jawaban Responden Mengenai Dimensi Convenience

Sesuai dengan rata-rata jawaban yang termasuk kategori ragu-ragu. Gambar di atas menunjukkan memang jumlah terbesar jawaban berada dalam kelompok ragu-ragu bahwa kenyamanan merupakan motivasi membeli makanan dan minuman di luar rumah.

Menyantap makanan dan minuman di luar rumah karena variasi makanan dan minuman yang beragam

\section{(100 responses)}

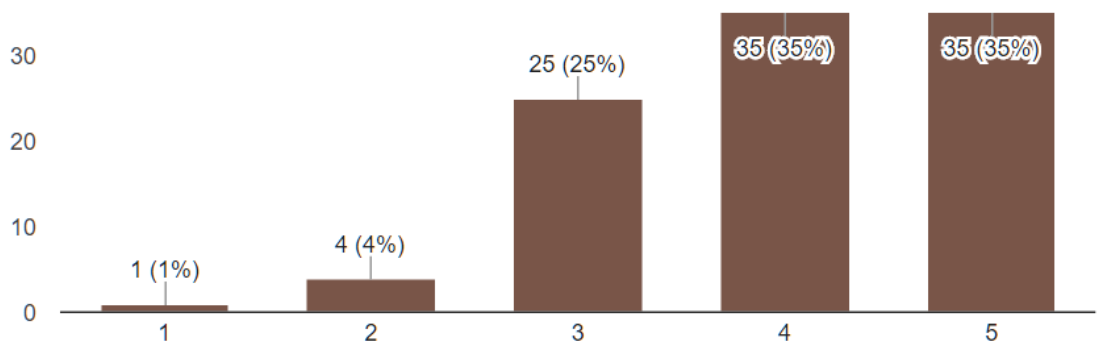

Gambar 2

\section{Sebaran Data Jawaban Responden Mengenai Dimensi Variety}

Seperti yang dijelaskan sebelumnya, terlihat juga pada gambar bahwa wajar jika nilai dimensi variasi adalah yang tertinggi. Secara total $70 \%$ pelanggan menjawab bahwa mereka setuju dan sangat setuju bahwa mereka menikmati makanan dan minuman di luar rumah karena variasi makanan yang lebih beragam. 
Menyantap makanan dan minuman di luar rumah karena tidak perlu menyiapkan makanan dan minuman sendiri

(100 responses)

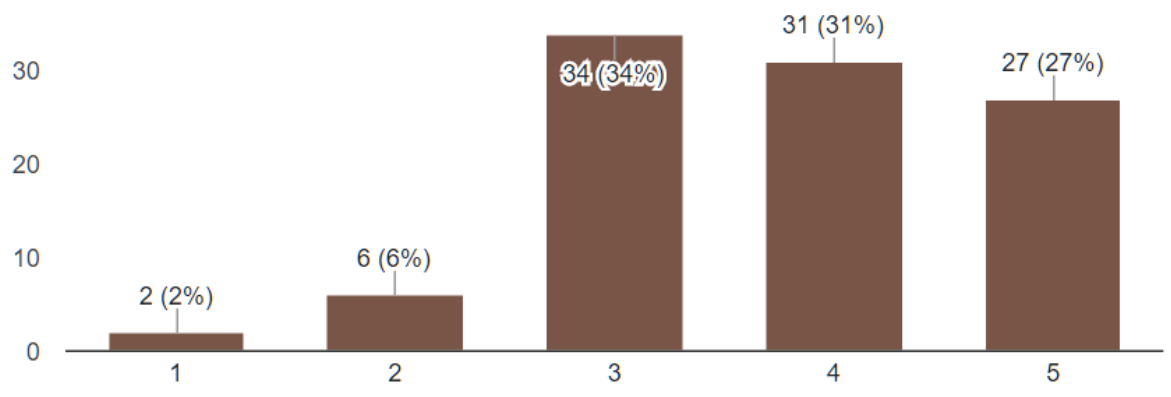

Gambar 3

Sebaran Data Jawaban Responden Mengenai Dimensi Labour

Dimensi labour yang berarti tenaga kerja menunjukkan bahwa pelanggan membeli makanan dan minuman di luar rumah supaya tidak perlu repot menyiapkan makanan sendiri juga mendapatkan nilai tinggi bahkan berada pada urutan kedua terbesar. Sehingga ini merupakan salah satu motivasi paling kuat bagi pelanggan ketika memilih makan dan minum di luar rumah.

Menyantap makanan dan minuman di luar rumah karena alasan status sosial (100 responses)

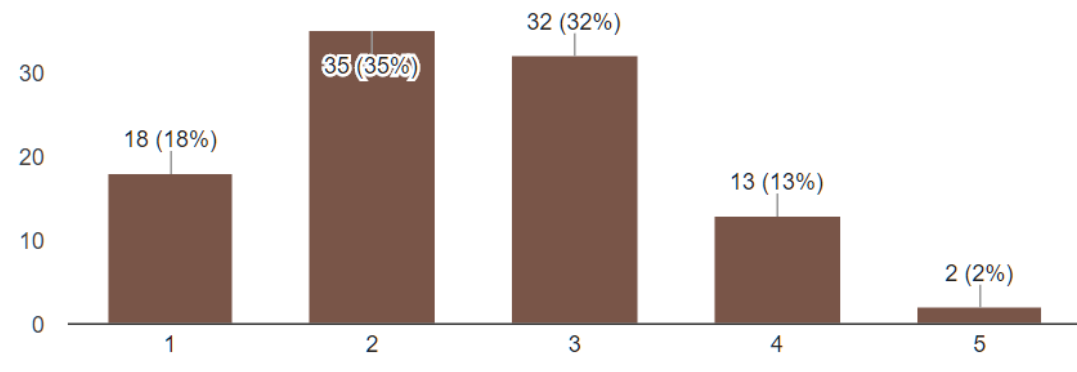

Gambar 4

Sebaran Data Jawaban Responden Mengenai Dimensi Status

Banyak jawaban berkisar antara setuju, tidak setuju dan ragu-ragu. Hal ini lah yang menyebabkan motivasi mengejar status sosial adalah motivasi terendah pelanggan untuk makan dan minum di luar rumah. 
Menyantap makanan dan minuman di luar rumah karena adanya event menarik

(100 responses)

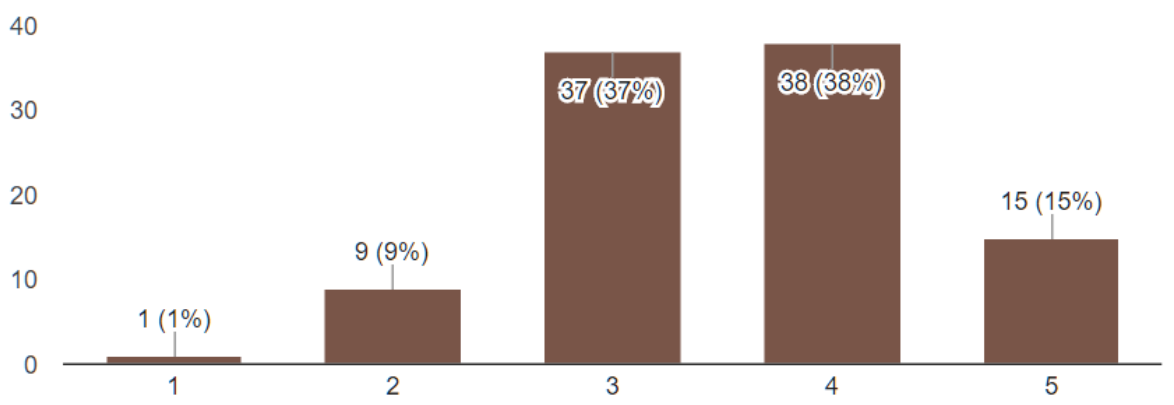

Gambar 5

Sebaran Data Jawaban Responden Mengenai Dimensi Culture/Tradition

Budaya atau tradisi diwakilkan dengan adanya event baik komersil maupun non komersil, kecil ataupun besar dan private ataupun umum. Sehingga motivasi di sini bisa makan di luar untuk merayakan hari ulang tahun, atau bahkan bisa juga karena adanya event festival makanan yang besar.

Menyantap makanan dan minuman di luar rumah karena adanya dorongan kebutuhan akan makanan dan minuman yang mendadak harus segera dipenuhi

(100 responses)

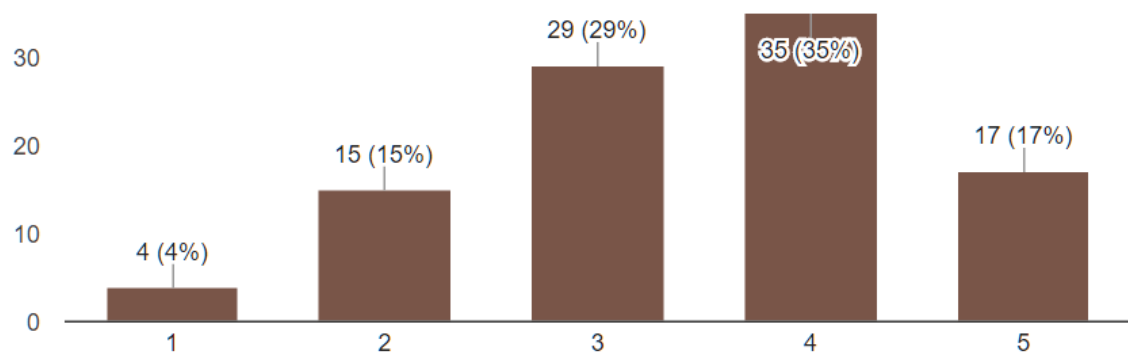

Gambar 6

Sebaran Data Jawaban Responden Mengenai Dimensi Impulse

Impulse adalah dorongan yang mendesak, seperti rasa lapar atau haus dahaga. Pelanggan menjawab bahwa mereka setuju motivasi mereka makan dan minum di luar adalah untuk memenuhi dorongan akan kebutuhan lapar dan haus yang mendesak harus dipenuhi. 
Menyantap makanan dan minuman di luar rumah karena tidak ada pilihan lain (100 responses)

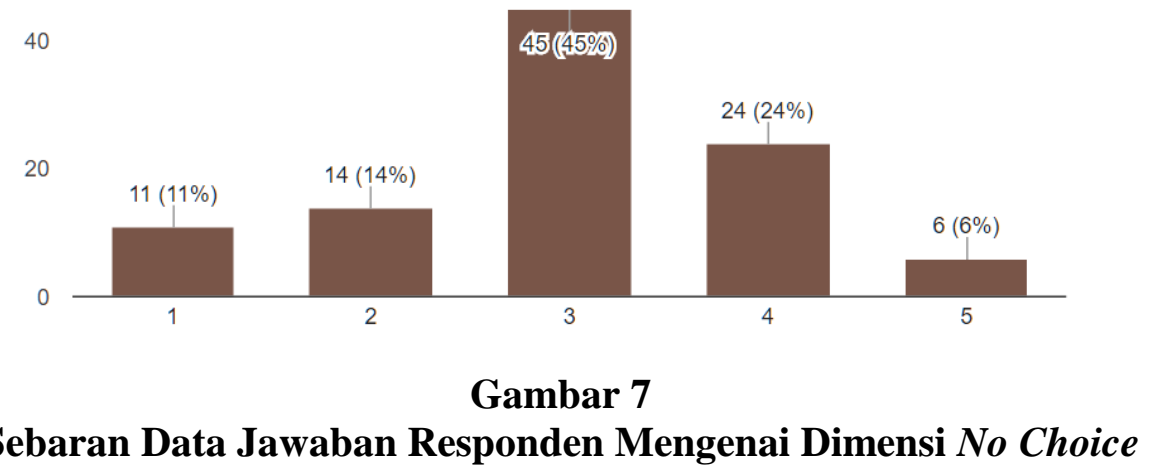

Pada dimensi terakhir, pelanggan merasa ragu jika motivasi makan dan minum di luar rumah dipicu oleh tidak adanya pilihan lain. Hal ini termasuk di dalamnya jika sedang dirawat di rumah sakit, penjara, seminar atau di tempattempat atau kondisi yang memang terpaksa menuntut mereka tidak makan di rumah.

\section{SIMPULAN}

Motivasi terkuat dari pelanggan ketika makan dan minum di luar rumah adalah karena mencari makanan dan minuman yang lebih bervariasi, atau dengan kata lain di luar kebiasaan juga bisa diartikan mencari makanan dan minuman yang baru. Selain itu alasan makan di luar yang kedua terbesar adalah agar tidak perlu menyiapkan makanan di rumah. Adapun motivasi terendah ketika orang makan di luar rumah yaitu untuk mengejar status sosial yang berarti ketika orang makan di suatu restoran yang mahal tidak selalu didasari oleh motivasi mengejar prestise.

\section{DAFTAR PUSTAKA}

Barrows, Clayton W., Tom Powers dan Dennis Reynolds. (2012). Introduction to Management In The Hospitality Industry Tenth Edition. John Wiley \& Sons, Inc.

Davis, Bernard, Andrew Lockwood, Peter Alcott dan Ioannis S. Pantelidis. (2008). Food and Beverage Management, Fourth Edition. Oxford UK: Elsevier Butterworth-Heinemann

Gillespie, Cailein dan John Cousins. (2011). European Gastronomy into the $21^{\text {st }}$ Century. New York: Routledge Taylor \& Francis Group. 
Hawkins, Del I. dan David L. Mothersbaugh. (2010). Consumer Behavior, Building Marketing Strategy, Eleventh Edition. United States of America: McGraw-Hill/Irwin.

Hoyer, Wayne D., Deborah J. MacInnis dan Rik Pieters. (2013). Consumer Behavior, Sixth Edition. United States of America: South-Western, Cengage Learning

Stanley, John dan Linda Stanley. (2015). Food Tourism A Practical Marketing Guide. UK: www.cabi.org

Lillicrap, Dennis dan John Cousins. (2010). Food and Beverage Service, Eighth Edition. London: Hodder Education

Solomon, Michael R. (2013). Consumer Behavior, Buying, Having, and Being, Tenth Edition. United States of America: Pearson Education, Inc.

Utama, I Gusti Bagus Rai dan Ni Made Eka Mahadewi. (2012). Metodologi Penelitian Pariwisata dan Perhotelan. Yogyakarta: Penerbit Andi.

Walker, John R. (2014). The Restaurant from Concept to Operation, Seventh Edition. New Jersey: John Wiley \& Sons, Inc

\section{Online:}

Tribunnews.com.http://www.tribunnews.com/bisnis/2014/04/02/dalam-5-tahunjumlah-restoran-kelas-menengah-tumbuh-250-persen. Diunggah: Rabu 2 April 2014. Diakses Kamis 3 November 2016 